\title{
Solute Excretion in Man during Changing Urine Flow Occurring Spontaneously and Induced by Vasopressin Injection *
}

\author{
S. Thomas \\ (From the Department of Physiology, University of Manchester, Manchester, England)
}

Studies of the effect of vasopressin on urinary excretion of electrolytes have usually compared urinary outputs or clearances before hormone injection, in periods of stable urine flows, to clearances after injection $(1$; see $2-4$ for reviews of the extensive literature). There are few data concerning solute excretion during the transition from diuresis to antidiuresis; in this phase, accumulation of progressively more concentrated fluid in the dead space of the renal tract invalidates conventional calculations of solute excretory rates and clearances, which require steady-state conditions $(5,6)$.

Study of the transition from diuresis to antidiuresis is, however, potentially useful in determining whether differences between medullary solute concentrations in diuresis and antidiuresis (7-10) and the operation of countercurrent mechanisms $(11,12)$ involve changes in tubular solute transport. Furthermore, nonsteady-state conditions can provide information about renal solute transport mechanisms, as in Chinard's technique of comparing urinary concentrations before and after injection of solutes into the renal artery (13).

Accordingly, I have determined changes in solute concentrations in samples obtained as frequently as possible during the rapid decline in flow after iv injection of vasopressin. A similar technique was recently used in the dog (14). The rationale of the present experimental design is that if the only event involved in urinary concentration is the abstraction of water from the nephron, then changes in the concentrations of the various urinary solutes, relative to those in

\footnotetext{
* Submitted for publication December 17, 1962 ; accepted September 11, 1963.

Reported in part at a Colloquium on Hormones and the Kidney, organized by the Society for Endocrinology, at Cambridge, England, September 19-21, 1962.
}

diuretic periods, should be equal for all solutes. If a change also occurs in tubular reabsorption of some solute, its increase in urinary concentration, relative to a preceding diuretic steady state, would be different from that of another solute. In particular, a change in the concentration of solute compared with that of a "glomerular substance" (13) such as inulin would provide an index of the direction and magnitude of any change in tubular solute transport.

\section{Methods}

Group I experiments, performed on five healthy male subjects, ages 23 to 42 years, provide data on the relationship between endogenous creatinine and inulin excretion in a wide variety of circumstances, including changes in urine flow. The experiments were originally designed as investigations on phosphate $\mathrm{Tm}$ (15) and on the acute renal effects of cortisone and hydrocortisone in man (16). Full technical details of experimental procedures were given in previous publications $(15,16)$; other details are presented in the Results.

Groups II experiments were performed on three healthy males, ages 28,36 , and 46 years, who had previously been on normal diets. After a morning of performing routine laboratory duties, subjects emptied their bladders between 1 p.m. and 2 p.m., sat down, and drank a large dose of water $(20 \mathrm{ml}$ per $\mathrm{kg}$ body wt) within 5 to 15 minutes. The water load was subsequently maintained constant by drinking a volume equal to the volume of urine voided; no correction was made for insensible loss of water. Subject $\mathrm{M}$ drank beer ( $\mathrm{Na}$ content, 7.5 $\mathrm{mEq}$ per $\mathrm{L}$; $\mathrm{K}$ content, $12 \mathrm{mEq}$ per $\mathrm{L}$ ) in place of water, the alcohol content serving as an additional assurance of suppression of endogenous vasopressin production. Because of this difference in procedure and because plasma urea concentration declined during vasopressin experiments in this subject, a control experiment was performed with no vasopressin injected and a constant fluid load maintained by drinking beer.

Once maximal flows were attained, urine collections were made by voluntary voiding at $5-$ to 10 -minute intervals for several successive periods to ensure that a stable diuresis was sustained. Vasopressin 1 (0.5 $\mathrm{mU}$

\footnotetext{
${ }^{1}$ Pitressin, Parke, Davis, Detroit, Mich.
} 
per $\mathrm{kg}$ body wt) was then injected within 1 to 2 minutes via an indwelling polyethylene cannula inserted into a forearm vein at the beginning of the experiment. The times of injection in the two experiments on each subject differed; therefore possible diurnal rhythmic changes in solute excretion occurring during the developing antidiuresis in one experiment could be assessed against equivalent control diuretic periods in the other.

During the decrease in urine flow, collections were made as often as was considered likely to give complete bladder emptying, or at least $10 \mathrm{ml}$ of urine, and was accordingly adjusted with the time after vasopressin injection. Collections were then continued at less frequent intervals until flows had returned towards or to the preinjection diuretic values.

Blood samples were collected at intervals via the polyethylene cannula, received into heparinized tubes, centrifuged immediately, and the plasma pipetted off.

Analytical methods. Creatinine determinations on urine were made by the method of Bonsnes and Taussky (17) and on plasma by that of Brod and Sirota (18); inulin by the method of Dick and Davies (19); urea by the microdiffusion method of Conway (20), subtracting an ammonia blank or, occasionally, the ammonia concentration as determined by aeration and titration (21); osmolality by a modification of the freezing-point depression method of Johlin (22); sodium and potassium by flame photometry; and chloride by electrometric titration (23).

\section{Results}

Group I experiments: comparison of creatinine and inulin excretion. Unpublished data obtained in previous experiments $(15,16)$ have been ex-

TABLE I

Comparisons of inulin and endogenous creatinine excretion*

\begin{tabular}{|c|c|c|c|c|c|}
\hline \multirow{2}{*}{$\begin{array}{l}\text { No. } \\
\text { of } \\
\text { sub-- } \\
\text { jects }\end{array}$} & \multirow{2}{*}{$\begin{array}{c}\text { No. } \\
\text { of } \\
\text { periods }\end{array}$} & \multirow{2}{*}{$\begin{array}{l}\text { Range of } \\
\text { initial urine } \\
\text { flows }\end{array}$} & \multicolumn{3}{|c|}{ Creatinine/inulin ratio } \\
\hline & & & Mean & $\mathrm{SE}$ & Range \\
\hline \multicolumn{6}{|c|}{$\begin{array}{l}\quad m l / m i n \\
\text { A. Stable flows, phosphate infusions. } \dagger \quad R_{1}=C_{C_{r}} / C_{I_{n}}\end{array}$} \\
\hline 4 & 23 & $1.55-16.55$ & 1.03 & 0.02 & $0.92-1.16$ \\
\hline \multicolumn{3}{|c|}{$\begin{array}{l}\text { B. Flows decreased at least } \\
\text { Ucr } / \mathrm{UIn}_{\text {In, period } 1}\end{array}$} & \multicolumn{3}{|c|}{$25 \% . \ddagger R_{2}=U_{c_{r}} / U_{I_{n}}$ period 2} \\
\hline 4 & 13 & $2.80-18.04$ & 1.02 & 0.02 & $0.93-1.16$ \\
\hline \multicolumn{3}{|c|}{$\begin{array}{l}\text { C. Flows increased at least } \\
U_{C_{r} / U_{I n} \text { period } 1}\end{array}$} & \multicolumn{3}{|c|}{$25 \% . \ddagger \mathrm{R}_{3}=\mathrm{U}_{\mathrm{Cr}} / \mathrm{U}_{\mathrm{In}}$, period 2} \\
\hline 5 & 17 & $2.25-12.10$ & 1.00 & 0.02 & $0.85-1.18$ \\
\hline & & p, that: $\begin{aligned} \mathbf{R}_{1} & =\mathbf{1 . 0} \\
\mathbf{R}_{2} & =\mathbf{1 . 0} \\
\mathbf{R}_{\mathbf{3}} & =\mathbf{1 . 0} \\
\mathbf{R}_{2} & =\mathbf{R}_{\mathbf{3}}\end{aligned}$ & $\begin{array}{r}0.1>p \\
0.4>p \\
1.0>p \\
p\end{array}$ & $\begin{array}{l}>0.05 \\
>0.3 \\
>0.9 \\
=0.6\end{array}$ & \\
\hline
\end{tabular}

$* \mathrm{R}=$ creatinine to inulin ratio, $\mathrm{C}=$ clearance, $\mathrm{In}=$ inulin, $\mathrm{Cr}=$ creatinine, and $U=$ urine.

$\dagger$ Data derived from published experiments (15).

$\ddagger$ Data derived from published experiments $(15,16)$. amined with reference to $a$ ) comparison of endogenous creatinine and inulin clearances during periods with stable urine flows and plasma concentrations and $b$ ) comparison of changes in urinary concentrations of creatinine and inulin in periods when abrupt changes in flow occurred. The results, together with a statistical analysis, are presented in Table I.

Under steady-state conditions during phosphate infusions for determinations of phosphate $\mathrm{Tm}$, the mean creatinine to inulin clearance ratio $\left(R_{1}\right.$, Table IA) was 1.03 in 23 comparisons on 4 subjects (D, Y, M, and $T$ ) (15). The small difference from a value 1.0 did not quite reach conventional levels of statistical significance $(0.1>p>$ $0.05)$.

In a wide range of experimental procedureswith and without phosphate infusion, with and without cortisone or hydrocortisone injection, in the morning and afternoon-abrupt changes in urine flow sometimes occurred with consequent changes in urinary creatinine and inulin concentrations. In some periods a change in hydration or the previous performance of a painful or nauseous procedure may have caused a change in the endogenous production of vasopressin; in others the causes of such changes in flow were uncertain. Tables IB and IC present the relative changes in urinary creatinine and inulin concentrations on 30 such occasions during 19 experiments on 5 subjects (D, L, M, T, and Y) $(15,16)$ in whom the flow increased or decreased abruptly by at least $25 \%$.

There was no significant change in creatinine to inulin urinary concentration ratio from one period to the next, either when the flow decreased $\left(R_{2}\right.$, Table IB) or increased $\left(R_{3}\right.$, Table IC) from a wide range of initial values; there was also no significant difference between the ratio observed during decreasing flows, $R_{2}$, and that found during increasing flows, $R_{3}(p=0.6)$.

These results point to the conclusions that during alterations in urine flow the relative changes in urinary creatinine and inulin concentrations are similar and that creatinine may be used as an index of changes in tubular water content.

Group II experiments: constant water load. Detailed data from the control experiment $\mathrm{Mc}$, in which vasopressin was not administered, are given 
TABLE II

Data during maintenance of constant water load, experiment $M c^{*}$

\begin{tabular}{|c|c|c|c|c|c|c|c|c|c|c|c|}
\hline \multirow[b]{2}{*}{ Time } & \multirow{2}{*}{$\begin{array}{l}\text { Urine } \\
\text { flow }\end{array}$} & \multicolumn{7}{|c|}{ Urinary concentration } & \multicolumn{3}{|c|}{$\mathrm{U} / \mathrm{P}$ ratio } \\
\hline & & Uosm & $\mathrm{UCr}_{\mathbf{r}}$ & UUrea & $\mathrm{U}_{\mathrm{Na}}$ & $U_{K}$ & $\mathrm{Ucl}_{\mathrm{c}}$ & $\overline{U_{N H 4}}$ & $\overline{\text { Osm }}$ & $\mathrm{Cr}$ & $\overline{\text { Urea }}$ \\
\hline $\min$ & $m l / m i n$ & $\begin{array}{l}\text { Osm } / \text { kg } \\
\quad \text { Subject }\end{array}$ & $\begin{array}{l}m g / L \\
M(46\end{array}$ & $\begin{array}{c}\text { mmoles } / L \\
\text { ars, } 1.83 \mathrm{~m}\end{array}$ & $m E q / L$ & $m E q / L$ & $m E \boldsymbol{q} / L$ & $m E q / L$ & & & \\
\hline $14.57-$ & & & & & & & & & & & \\
\hline $15.16 \frac{1}{2}-$ & 10.92 & 94 & 114 & 40.5 & 22 & 3.3 & 12 & 1.9 & 0.32 & 10.4 & 7.55 \\
\hline $15.27-$ & 12.33 & 84 & 102 & 34.9 & 21 & 2.2 & 11 & 1.7 & 0.29 & 9.38 & 6.71 \\
\hline $15.42-$ & 11.13 & 84 & 106 & 36.0 & 20 & 2.0 & 9.7 & 1.9 & 0.29 & 9.76 & 7.10 \\
\hline $15.57 \frac{1}{2}-$ & 12.20 & 80 & 103 & 34.0 & 19 & 1.9 & 8.7 & 1.8 & 0.27 & 9.67 & 6.82 \\
\hline $16.17 \frac{1}{2}-$ & 12.50 & 75 & 97.6 & 31.8 & 19 & 1.7 & 8.0 & 1.4 & 0.25 & 9.12 & 6.53 \\
\hline $16.29 \frac{1}{2}$ & 11.58 & 70 & 101 & 31.3 & 16 & 1.8 & 7.4 & 1.6 & 0.23 & 9.36 & 6.52 \\
\hline
\end{tabular}

$*$ Osm $=$ osmolality, $\mathrm{U} / \mathrm{P}$ ratio $=$ urine to plasma concentration ratio.

TABLE III

Data from diuretic periods immediately preceding, and periods of maximal concentrations subsequent to, vasopressin injection

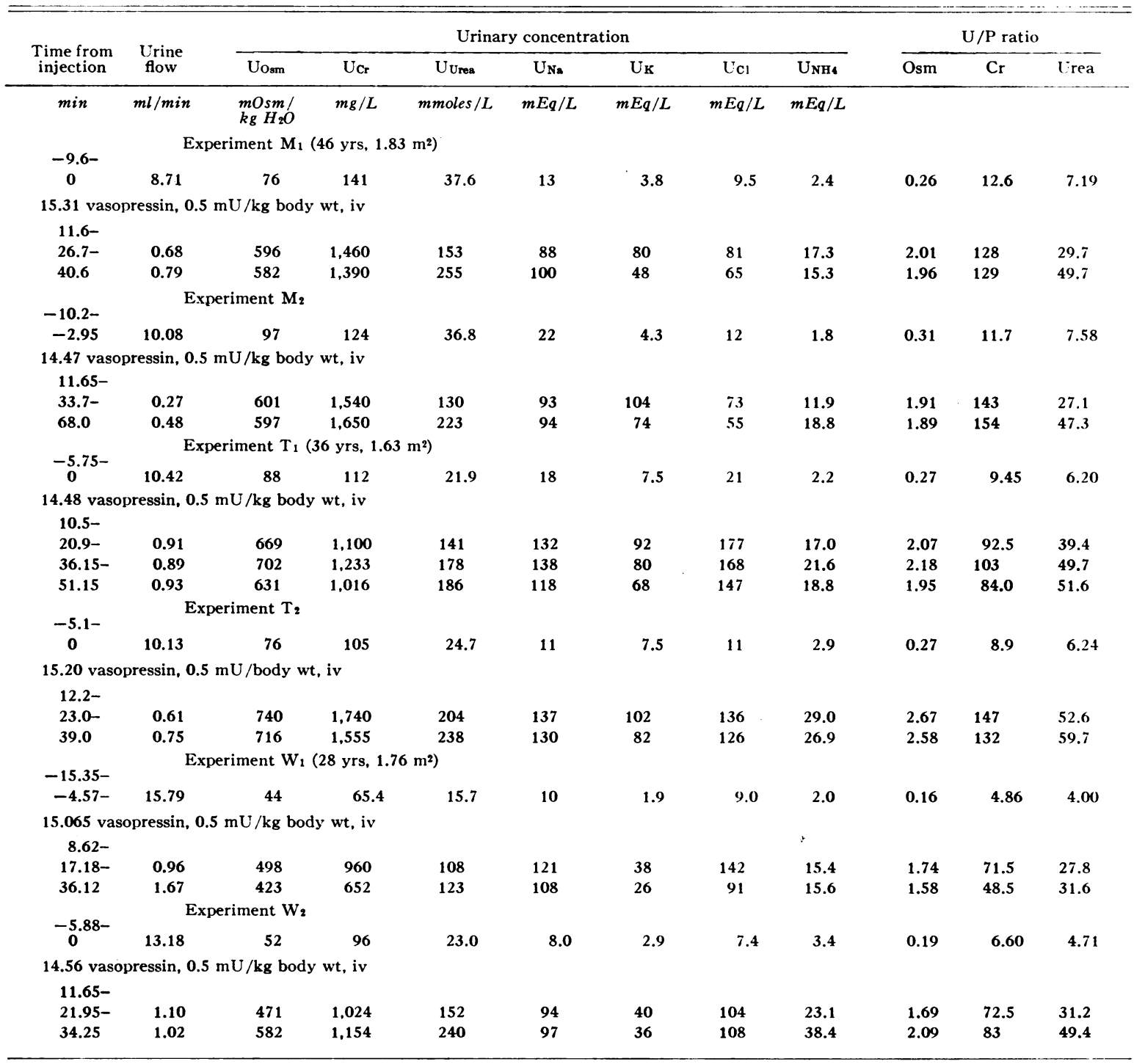


in Table II. Urine flow remained fairly constant, with only small changes in the urinary concentration and clearance of creatinine. The progressive falls in urinary osmolality, sodium, and potassium concentrations are considered to be manifestations of diurnal electrolyte excretory rhythms. A similar decline in urine urea concentration was accompanied by a fall in plasma urea concentration from 5.53 mmoles per $\mathrm{L}$ at 14.49 minutes to 4.78 mmoles per $\mathrm{L}$ at 16.32 minutes; consequently urea urine to plasma $(\mathrm{U} / \mathrm{P})$ concentration ratio and urea clearance remained more constant.
Similar data for the diuretic periods immediately preceding vasopressin injection in all experiments are presented in Table III. In Figures 1 and 3 , urinary concentrations in preceding and succeeding samples are given as ratios relative to concentrations in the control diuretic periods, since, in the present context, differences in the relative changes in concentration are considered to be significant. The concentrations of some solutes remained stable in the preliminary periods, but there was a progressive change in concentration and output of other solutes. In ex-

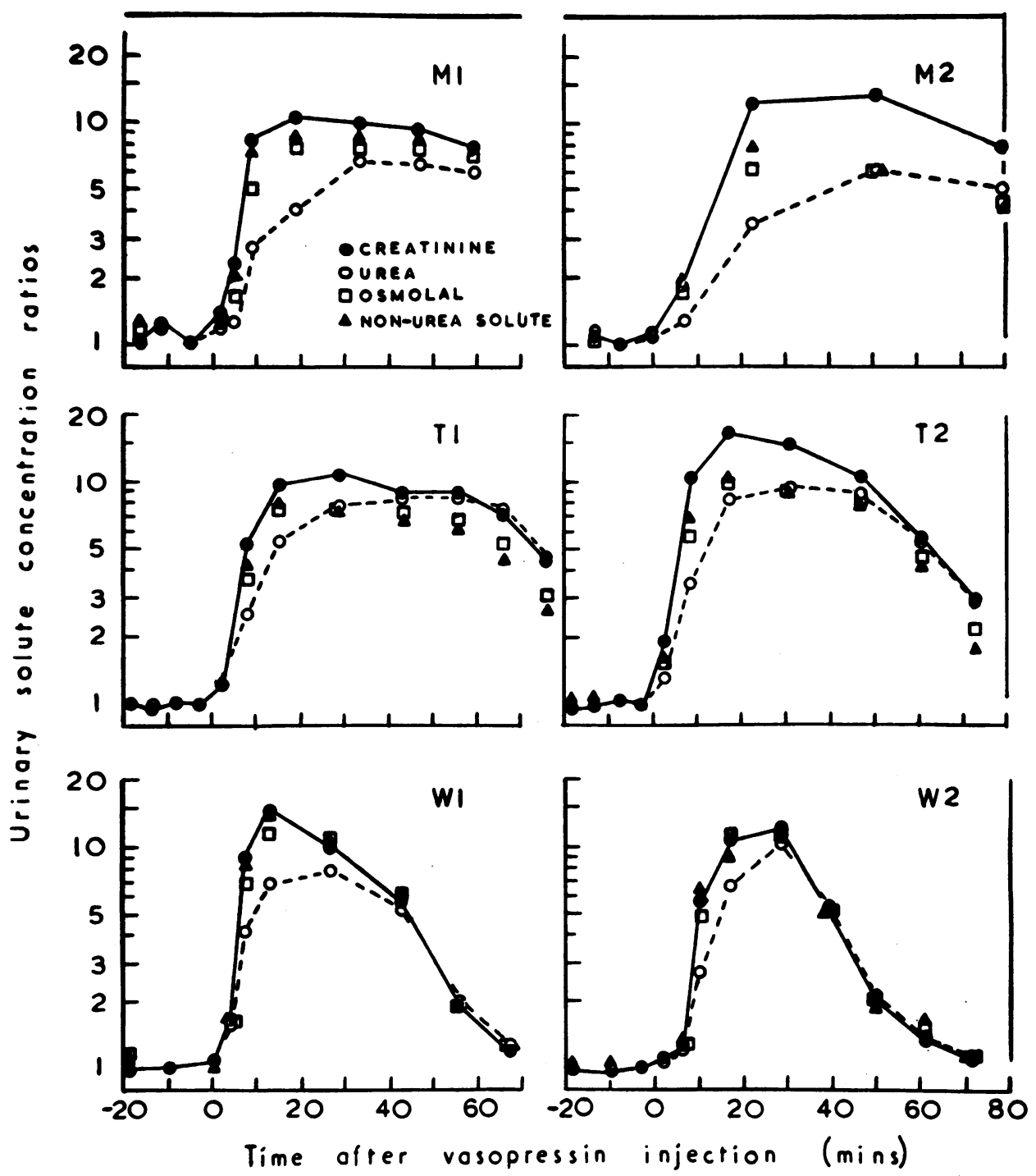

Fig. 1. URinary osmolality, UREa, NONUREa SOLUTE, aNd CREATINine CONCENTRations. These are ratios relative to control diuretic values given in Table III; vasopressin injection at zero time. 
periment $\mathrm{M}_{2}$ a spontaneous fall in urea concentration occurred; in some experiments urinary osmolality tended to fall, particularly when sodium concentration also declined. These changes, like those noted in experiment $\mathrm{Mc}$, are considered to be effects of diurnal excretory rhythms.

Vasopressin injection. The latent period between vasopressin injection and the earliest detectable change in water excretion, a rise in creatinine $U / P$ ratio or urinary concentration, was 3 to $5 \frac{1}{2}$ minutes. The magnitude and duration of the antidiuresis differed between subjects (Figures 1 and 3); individual data are therefore presented. Maximal urinary concentrations are included in Table III; note that the times at which these were attained were not simultaneous for all solutes (see Figures 1 and 3).

If changes in urinary concentration were due entirely to altered water reabsorption, then the increases in concentrations relative to the preceding diuretic state would be similar for all urinary solutes. The relative changes in creatinine, urea, osmolality, and nonurea solute (osmolalurea) concentrations are given in Figure 1 and sodium, potassium, ammonium, and creatinine concentrations in Figure 3. Comparison of the relative changes shows that during the developing antidiuresis there were marked and consistent differences for some solutes and that the magnitude of such differences varied in time.
Osmolality and urea concentrations. Within 3 to 10 minutes of vasopressin injection, the increment in urea concentration ratio was evidently less than that of any other urinary constituent (Figure 1). The maximal deviation from osmolality and creatinine concentration ratios occurred during the developing antidiuresis before maximal urinary osmolality and creatinine concentrations were attained. Later, during periods of maximal antidiuresis and with the subsequent onset of diuresis in Subjects $T$ and $W$, these differences became smaller or disappeared. Similar differences between the relative changes in osmolality and creatinine concentrations are primarily attributable to altered urea excretion, since, except in experiments with marked changes in sodium concentration, creatinine and nonurea solute concentration ratios were similar (Figure 1).

The magnitude of the effect of decreasing urine flow on urea excretion is most clearly seen by plotting urea to creatinine clearance ratio (i.e., urea $U / P$ : creatinine $U / P$ ) against creatinine $\mathrm{U} / \mathrm{P}$ (Figure 2). If the conclusions concerning Group I experiments can be extended to the circumstances in vasopressin experiments, this shows the excreted proportion of filtered urea in each sample. Several points are obvious. First, urea excretion was lower during antidiuresis than in diuresis. Second, during the rapid fall in flow, urea excretion fell to values even lower than those

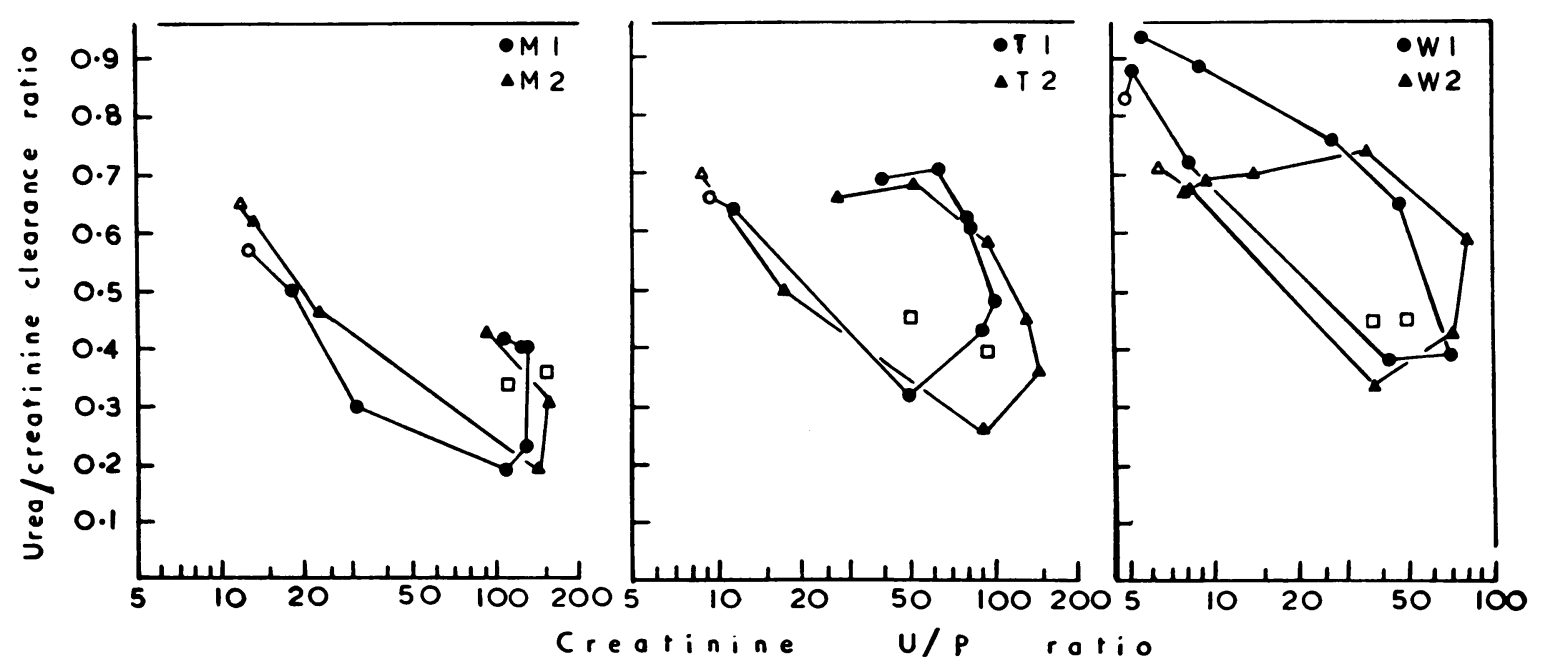

Fig. 2. Relation between URea to creatinine clearance ratio and Creatinine U/P Ratio im mediately PRECEDing $(O, \triangle)$ AND Following $(\bullet, \Delta)$ vasopressin injection. Minimal published values $(\square)$ at similar, stable urine flows are included for comparison $(24,25)$. 


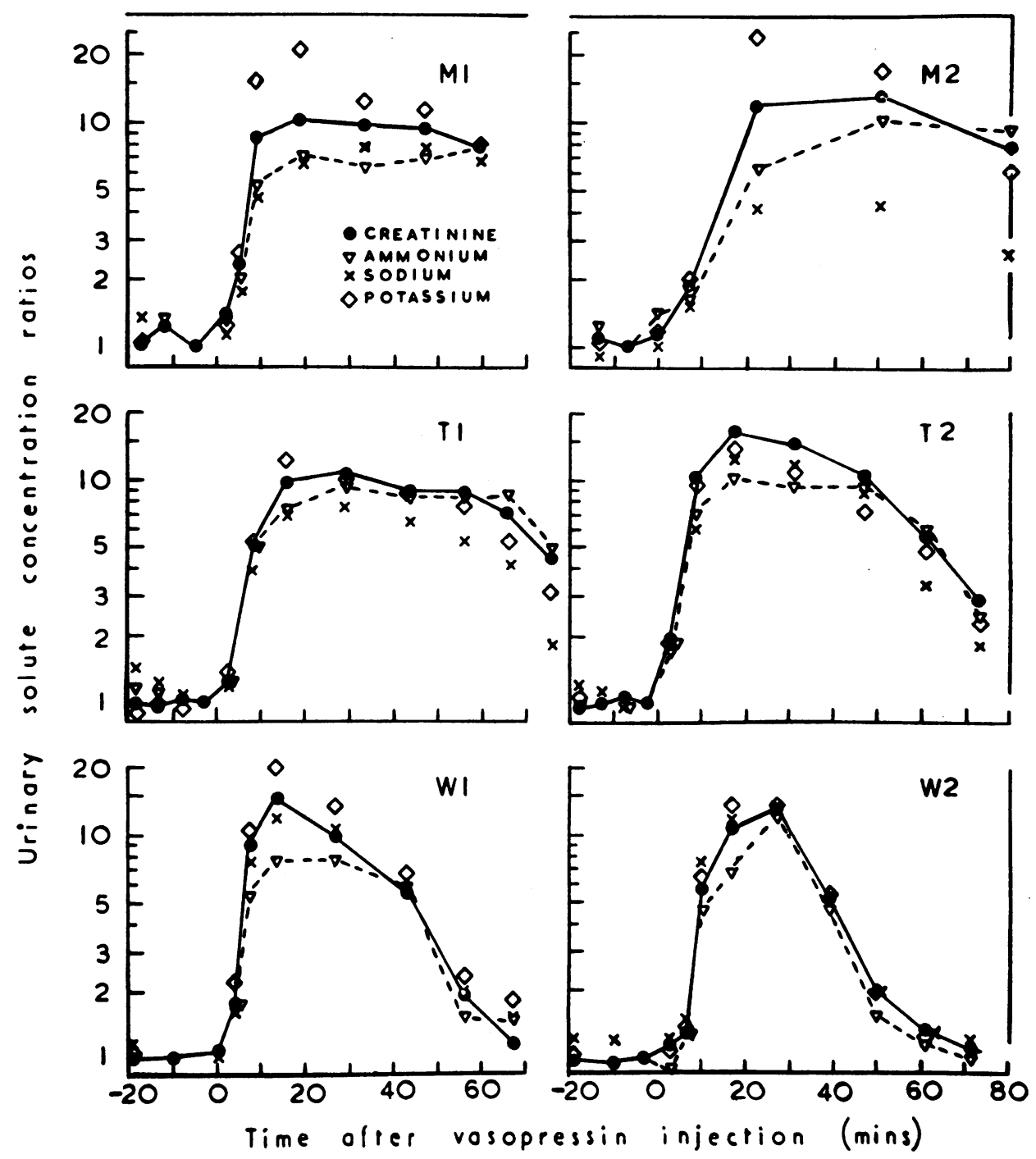

Fig. 3. Urinary Sodium, potassium, ammonium, and Creatinine concentrations. These are ratios relative to control diuretic values given in Table III; vasopressin injection at zero time.

observed during maximal or sustained antidiuresis. Urea excretion in this phase was less than the minimal values at similar, but stable, urine flows (inulin $\mathrm{U} / \mathrm{P}$ ratios) reported by other workers $(24,25)$; these values are included in Figure 2 for comparison. This large change in tubular urea transport was a rapid effect, occurring within 15 minutes of vasopressin injection in most experiments (Figure 1). Third, as low urine flows were sustained, a large increase in the excreted proportion of filtered urea occurred with little change in creatinine $U / P$ $\left(\mathrm{M}_{1}, \mathrm{M}_{2}\right.$, and $\left.\mathrm{W}_{2}\right)$. Finally, as urine flow sub- sequently increased, urea excretion increased towards the preinjection control values; only in $T_{1}$ did the clearance ratio exceed that found in the sample immediately prior to vasopressin injection, and even here the ratio fell within the range of values found in earlier diuretic control samples.

These effects on urea excretion are equally evident in similar plots of urea to nonurea solute clearance ratios against nonurea solute $U / P$ ratios.

Electrolyte concentrations. The increases in ammonium concentration ratio during the transition from diuresis to antidiuresis were also con- 
sistently smaller than those of creatinine (Figure 3 ), but were larger and evident earlier after vasopressin injection than the increases in urea ratio. Later, with the persistence of antidiuresis in $\mathrm{M}$ and the onset of diuresis in $\mathrm{T}$ and $\mathrm{W}$, the changes in ammonium concentration ratio showed no consistent differences from those of osmolality, urea, or creatinine.

Assessment of any effect of vasopressin on sodium excretion is difficult in view of the spontaneous fall in sodium concentration noted in some experiments. In experiments $W_{1}$ and $W_{2}$ the relative changes in sodium concentration were closely similar to those in creatinine and nonurea solute, whereas in experiments $M_{1}$ and $M_{2}$, the relative increases in sodium concentration were smaller (Figures 1 and 3 ).

Increases in potassium concentration ratio tended to be greater than those of other urinary constituents at some stages of the developing antidiuresis (Figure 3). In M, potassium ratio remained higher during the persistent antidiuresis; in the other subjects, this relative increase was more transient.

In every experiment, the sodium to potassium concentration ratio fell relative to that present in the diuretic control sample; again this fall was persistent in $\mathrm{M}$ but in $\mathrm{T}$ and $\mathrm{W}$ was only a transient event during the developing antidiuresis.

\section{Discussion}

The sequence of changes in urine flow after vasopressin injection and the rapidity of its effect on water reabsorption are well-known (26). The present Group II experiments show that the action of vasopressin on water excretion is accompanied by consistent effects on urea and ammonium excretion during the developing antidiuresis.

Interpretation of quantitative and temporal differences between changes in solute concentrations after vasopressin injection depends on the recognition and evaluation of other possible contributory factors: 1) Changes in plasma solute concentrations and urinary solute outputs over prolonged periods, because of variable hydration or diurnal excretory rhythms, were minimized by maintenance of a constant water load, by performance of the experiments in the afternoon, and by the choice of a single iv, rather than continuous, in- jection of vasopressin. Thus, changes in urine to plasma concentration ratios of osmolality, urea, nonurea solute, and creatinine were similar to those of urinary concentrations. Spontaneous variations in sodium excretion have, however, clearly contributed to the postvasopressin changes observed in some experiments. 2) Changes in glomerular filtration rate (GFR) cause unequal changes in the excretion of different urinary solutes $(27,28)$. Maintenance of a constant water load obviates changes in GFR that might follow variations in plasma volume and plasma protein concentration. The design of Group II experiments precluded valid calculations of GFR during the rapid changes in urine flow, but current theory suggests little effect of vasopressin on GFR (29). Both 3) accumulation of solute in the dead space of the renal tract because of abstraction of water and 4) bladder-emptying errors affect excretory rates, but since all urinary solutes would be equally affected, relative changes in concentrations would remain equal. Bladder-emptying errors would obscure, rather than enhance, the magnitude of differences in concentration ratios. 5) The use of endogenous creatinine as a "glomerular substance" might also cause differences between changes in solute concentrations. The extensive literature, with differing conclusions, on comparisons of creatinine and inulin clearances in man has been reviewed recently (30). The results of the present Group I experiments (Table I) are taken to validate the use of creatinine as an index of water reabsorption and of changes in tubular solute transport. Furthermore, the changes in urea and ammonium excretion are still evident when compared with urinary solutes other than creatinine, such as nonurea solute.

Many previous investigations on the relation between solute (e.g., urea) excretion and urine flow have employed variations in water intake as the means of inducing changes in flow. Consequently, factors 1 and 2 discussed above may have contributed to any observed changes in solute excretion. In view of these considerations, differences in the relative changes in solute concentrations after vasopressin injection in the present experiments are considered to be due to altered tubular transport.

If changes in solute excretion were due solely to altered intratubular concentrations, then the 
expected relation between solute output (or clearance) and urine flow might be similar to that classically described for urea during steady or slowly declining urine flow $(29$, p. 63$)$. In the present experiments, however, urea excretion fell to values lower than those previously observed at simliar but stable urine flows $(24,25)$ and even lower than those found in more concentrated urine samples (Figure 2). These observations are similar to those reported in the dog after vasopressin injection (14) and to a transient fall in urea clearance-“abatement"-in sheep (31). The phenomenon appears to be the converse of "exaltation"- a transient rise in urea clearance after water administration to values higher than those found at similar but steady flows, originally described by Shannon in the dog (32) and since observed in other species (33) including man (24).

These differences between urea excretion during steady and nonsteady urine flows suggest the operation of factors additional to changes in intratubular urea concentration. In terms of suggested actions of vasopressin (34), such factors might include a direct effect on tubular permeability to urea (35) or on an active transport mechanism (36). Alternatively, peritubular urea concentration may rise because of local accumulation in a sink or pool. Thus, if the collecting ducts are permeable to urea during antidiuresis $(12,33,35)$, delivery of more concentrated fluid from the distal tubule would lead to diffusion of urea into the medulla and a decrease in urea excretion. Operation of the medullary vasa recta as a countercurrent exchange system (12) would cause the sequestration of a pool of urea, progressively limiting further urea diffusion until a new steady state was attained; urea clearance would be lower than at similar but steady flows (Figure 2), and the changes in urine urea concentration, creatinine, and nonurea solute would differ in time and magnitude (Figure 1). With the establishment of a steady state of antidiuresis and of a medullary urea concentration gradient, net back diffusion of urea would be limited to that lost into the circulation; the increase in urea to creatinine clearance ratio at almost constant creatinine urine to plasma concentration ratio in the present experiments (Figure 2) is consistent with the attainment of such a steady state.
Similar considerations apply to the changes in ammonium concentration after vasopressin injection. Under steady-state conditions, the rate of excretion of ammonium is usually considered independent of urine flow (and so of intratubular ammonium concentration), except when the urine is alkaline $(37,38)$. The changes in ammonium concentration observed here therefore suggest the involvement of factors alternative or additional to increases in intratubular concentration. The pattern of change is again compatible with accumulation in a tubular sink or peritubular pool in the nonsteady state, although changes in intratubular $\mathrm{pH}$ cannot be excluded as a factor. Differences between ammonium and creatinine excretion induced by rapid injection into the dog's renal artery have similarly been explained by transitory diffusion of free ammonia into and out of a tubular sink (39). The existence of a medullary concentration gradient of ammonium during antidiuresis has not been specifically investigated but is evident in published data concerning the dog kidney (Table I) (9). Back diffusion of free ammonia from, or decreased diffusion into, the collecting duct might contribute to the generation of such a gradient.

The only consistent feature of changes in sodium and potassium excretion was a decrease in sodium to potassium concentration ratio, transient in 2 subjects; a similar change in the first 20 minutes after vasopressin injection in the dog was believed related to the large dose used, rather than a physiological accompanient of endogenous vasopressin secretion (14). In those experiments where spontaneous changes in sodium excretion were least evident, the similarity between changes in creatinine and nonurea solute concentrations (Figure 1) also argues against a marked over-all effect on electrolyte excretion during the developing antidiuresis.

The absence of any consistent difference between the relative changes in solute concentration ratios during the subsequent diuresis in $\mathrm{T}$ and $\mathrm{W}$ (Figures 1,3) means that these changes were primarily determined by diminished water reabsorption. During this phase, urea to creatinine clearance ratios did not clearly exceed the values of the preliminary diuretic periods (Figure 2), although the ratios were higher than most of the values at comparable, but stable, urine 
flows $(24,25)$; a fraction of the decrement in urea excretion during the developing antidiuresis was not excreted during the ensuing diuresis. These observations, together with the rapidity of the effect of vasopressin on urea excretion (Figure 1), are compatible with a change in tubular permeability to urea, as suggested by Jaenike (35) for the collecting duct of the dog. The relevant data, however, are too few to exclude other possibilities.

If the present observations can be related to the generation of solute concentration gradients in the renal medulla during antidiuresis, the accumulation of a medullary pool of urea, and possibly of ammonium, involves increased transport out of the tubule. The magnitude of the effect on urea excretion supports the suggestion (12) of a unique role of urea in the urinary concentrating process.

\section{Summary}

1. In 23 clearance periods with urine flows stable during phosphate infusions in 4 subjects, the mean creatinine to inulin clearance ratio was 1.03 ( $\pm \mathrm{SD}, 0.08$; probability that ratio is unity, $0.1>\mathrm{p}>0.05)$.

2. During 30 instances of spontaneous increases or decreases in urine flow in a variety of experimental circumstances-with and without phosphate infusion, with and without cortisone or hydrocortisone injection, in the morning and afternoon -there were no significant differences between changes in creatinine and inulin concentrations relative to those in the preceding urine samples.

3. In 2 experiments on each of 3 subjects maintained on a constant water load of $20 \mathrm{ml}$ per $\mathrm{kg}$ body weight, changes in osmolal, endogenous creatinine, urea, nonurea solute (osmolal-urea), sodium, potassium, and ammonium concentrations induced by vasopressin injection were compared in successive frequent urine samples during the rapid fall in urine flow: a) During the decline in urine flow, the increments in osmolality and urea concentrations (and $U / P$ ratios) relative to those in the preceding diuretic periods were smaller than those in creatinine and nonurea solute concentrations (and U/P ratios); urea to creatinine clearance ratios fell transiently to values smaller than those previously reported at similar but steady urine flows, with minimal values attained before maximal creatinine and nonurea solute concentrations (or U/P ratios). b) Ammonium excretion relative to that of creatinine or nonurea solute also fell. c) There were no consistent differences between the changes in nonurea solute and creatinine concentrations.

4. After maximal antidiuresis, the relative changes in urinary concentrations were not consistently different for any solute.

5. The quantitative and temporal pattern of the changes in urea and ammonium concentrations during the developing antidiuresis is consistent with accumulation in a tubular sink or peritubular pool, probably contributing to the generation of medullary concentration gradients.

\section{References}

1. Thomson, W. B. The effect of oxytocin and vasopressin and of phenylalanyl ${ }^{3}$-oxytocin on the urinary excretion of water and electrolytes in man. J. Physiol. (Lond.) 1960, 150, 284.

2. Selkurt, E. E. Sodium excretion by the mammalian kidney. Physiol. Rev. 1954, 34, 287.

3. Thorn, N. A. Mammalian antidiuretic hormone. Physiol. Rev. 1958, 38, 169.

4. Wesson, L. G., Jr. Hormonal influences on renal function. Ann. Rev. Med. 1961, 12, 77.

5. Bojesen, E. The transport of urine in the upper urinary tract. Acta physiol. scand. 1954, 32, 39.

6. Wesson, L. G., Jr. Glomerular and tubular factors in the renal excretion of sodium chloride. Medicine (Baltimore) 1957, 36, 281.

7. Ullrich, K. J., and K. H. Jarausch. Untersuchungen zum Problem der Harnkonzentrierung und Harnverdunnung. Uber die Verteilung von Elektrolyten ( $\mathrm{Na}, \mathrm{K}, \mathrm{Ca}, \mathrm{Mg}, \mathrm{Cl}$, anorgenischem Phosphat), Harnstoff, Aminosäuren und exogenen Kreatinin in Rinde und Mark der Hundeniere bei verschiedenen Diuresezuständen. Pflügers. Arch. ges. Physiol. 1956, 262, 537.

8. Bray, G. A. Freezing point depression of rat kidney slices during water diuresis and antidiuresis. Amer. J. Physiol. 1960, 199, 915.

9. Levitin, H., A. Goodman, G. Pigeon, and F. H. Epstein. Composition of the renal medulla during water diuresis. J. clin. Invest. 1962, 41, 1145.

10. Gottschalk, C. W. Micropuncture studies of tubular function in the mammalian kidney. Physiologist 1961, 4, 35.

11. Wirz, H., B. Hargitay, and W. Kuhn. Lokalisation des Konzentrierungsprozesses in der Niere durch direkte Kryoskopie. Helv. physiol. pharmacol. Acta. 1951, 9, 196.

12. Berliner, R. W., N. G. Levinsky, D. G. Davidson, and $M$. Eden. Dilution and concentration of the 
urine and the action of antidiuretic hormone. Amer. J. Med. 1958, 24, 730.

13. Chinard, F. P. Comparative renal excretions of glomerular substances following 'instantaneous' injection into a renal artey. Amer. J. Physiol. 1955, $180,617$.

14. Jaenike, J. R. Acute effects of the administration of vasopressin during water diuresis in the dog. $\mathrm{J}$. clin. Invest. 1963, 47, 161.

15. Longson, D., J. N. Mills, S. Thomas, and P. A. Yates. Handling of phosphate by the human kidney at high plasma concentrations. J. Physiol. (Lond.) 1956, 131, 555.

16. Mills, J. N., and S. Thomas. The acute effects of cortisone and cortisol upon renal function in man. J. Endocr. 1958, 17, 41.

17. Bonsnes, R. W., and H. H. Taussky. On the colorimetric determination of creatinine by the Jaffe reaction. J. biol. Chem. 1945, 158, 581.

18. Brod, J., and J. H. Sirota. The renal clearance of endogenous "creatinine" in man. J. clin. Invest. 1948, 27, 645.

19. Dick, A., and C. E. Davies. Measurements of the glomerular filtration rate and the effective renal plasma flow using sodium thiosulphate and p-amino-hippuric acid. J. clin. Path. 1949, 2, 67.

20. Conway, E. J. Microdiffusion Analysis and Volumetric Error. London, Crosby, Lockwood and Son, 1957.

21. Hawk, P. B., B. L. Oser, and W. H. Summerson. Practical Physiological Chemistry, 12th ed. London, Churchill, 1947, p. 828.

22. Johlin, J. M. The freezing point determination of physiological solutions. The usual errors and their elimination. J. biol. Chem. 1931, 91, 551.

23. Sanderson, P. H. Potentiometric determination of chloride in biological fluids. Biochem. J. 1952, 52, 502.

24. Chasis, H., and H. W. Smith. The excretion of urea in normal man and in subjects with glomerulonephritis. J. clin. Invest. 1938, 17, 347.

25. Murdaugh, H. V., Jr., B. Schmidt-Nielsen, E. M. Doyle, and R. O'Dell. Renal tubular regulation of urea excretion in man. J. appl. Physiol. 1956, 13, 263.
26. O'Connor, W. J. Renal Function. London, Arnold, 1962 , p. 36.

27. Lauson, H. D., and D. D. Thompson. Effects in dogs of decrease in glomerular filtration rate on cation excretion during intravenous administration of unreabsorbable anions. Amer. J. Physiol. 1958, 192, 198.

28. Davidson, D. G., N. G. Levinsky, and R. W. Berliner. Maintenance of potassium excretion despite reduction of glomerular filtration during sodium diuresis. J. clin. Invest. 1958, 37, 548.

29. Smith, H. W. The Kidney. Structure and Function in Health and Disease. New York, Oxford University, 1951, pp. 63, 258.

30. Doolan, P. D., E. L. Alpen, and G. B. Theil. A clinical appraisal of the plasma concentration and endogenous clearance of creatinine. Amer. J. Med. 1962, 32, 65.

31. Schmidt-Nielsen, B., H. Osaki, H. V. Murdaugh, Jr., and $R$. O'Dell. Renal regulation of urea excretion in sheep. Amer. J. Physiol. 1958, 194, 221.

32. Shannon, J. A. Glomerular filtration and urea excretion in relation to urine flow in the dog. Amer. J. Physiol. 1936, 117, 206.

33. Schmidt-Nielsen, B. Urea excretion in mammals. Physiol. Rev. 1958, 38, 139.

34. Kleeman, C. R., and R. E. Cutler. The neurohypophysis. Ann. Rev. Physiol. 1963, 25, 385.

35. Jaenike, J. R. The influence of vasopressin on the permeability of the mammalian collecting duct to urea. J. clin. Invest. 1961, 40, 144.

36. Bray, G. A., and A. S. Preston. Effect of urea on urine concentration in the rat. J. clin. Invest. 1961, 40, 1952.

37. Orloff, J., and R. W. Berliner. The mechanism of the excretion of ammonia in the dog. J. clin. Invest. 1956, 35, 223.

38. MacKnight, A. D. C., J. M. MacKnight, and J. R. Robinson. The effect of urinary output upon the excretion of 'ammonia' in man. J. Physiol. (Lond.) 1962, 163, 314.

39. Balagura, S., and R. F. Pitts. Excretion of ammonia injected into renal artery. Amer. J. Physiol. 1962, 203, 11. 